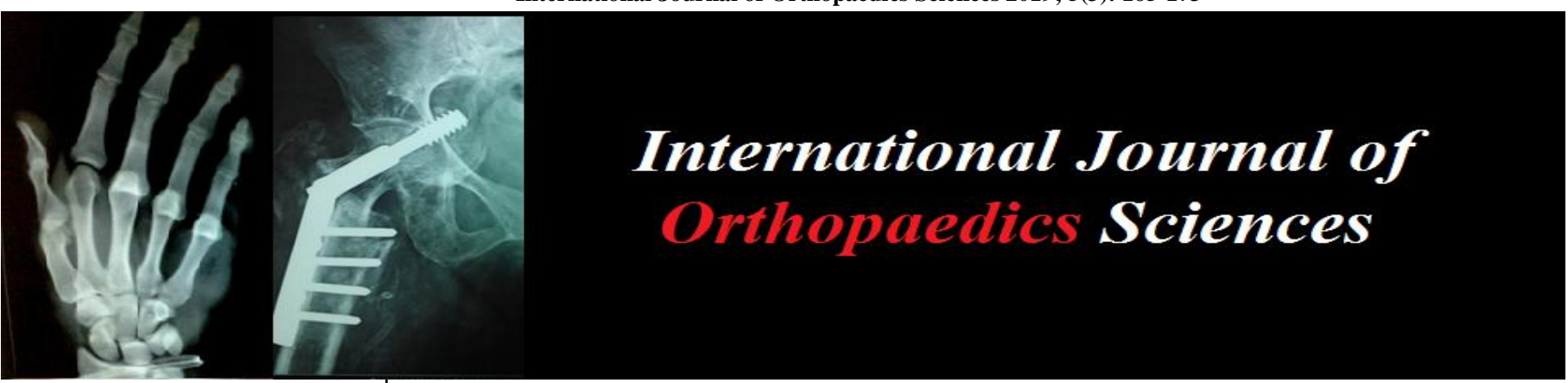

ISSN: $2395-1958$

IJOS 2019; 5(3): 165-173

(C) 2019 IJOS

www.orthopaper.com

Received: 01-05-2019

Accepted: 05-06-2019

\section{Kumar Shantanu}

Associate Professor, Department of Orthopaedic Surgery, King

George Medical University.

Lucknow, Uttar Pradesh, India

\section{Shailendra Singh}

Assistant Professor, Department of Orthopaedic Surgery, King George Medical University.

Lucknow, Uttar Pradesh, India

\section{Sibananda Ratha}

Senior Resident, Department of

Orthopaedic Surgery, King

George Medical University.

Lucknow, Uttar Pradesh, India

\section{Deepak Kumar}

Assistant Professor, Department of Orthopaedic Surgery, King

George Medical University.

Lucknow, Uttar Pradesh, India

\section{Vineet Sharma}

Professor, Department of Orthopaedic Surgery, King George Medical University. Lucknow, Uttar Pradesh, India

Correspondence

\section{Sibananda Rath}

Senior Resident, Department of

Orthopaedic Surgery, King

George Medical University.

Lucknow, Uttar Pradesh, India

\section{Comparative study of functional outcomes of arthroscopic ACL reconstruction by augmented hamstring graft with Fiber tape and hamstring graft alone: A prospective study}

\section{Kumar Shantanu, Shailendra Singh, Sibananda Ratha, Deepak Kumar and Vineet Sharma}

DOI: $\underline{\text { https://doi.org/10.22271/ortho.2019.v5.i3d.1526 }}$

Abstract

Background: Study is carried out to measure the additional effect of using Fiber-tape on functional outcome of anterior cruciate ligament tear managed by augmenting ACL reconstruction with Fiber tape.

Methods: The standardised, Anterior Drawer test Lachman test, Pivot shift test, Lysholm knee score quantified in terms of the side-to-side difference in laxity both preoperatively and postoperatively.

Result: The present study was conducted on patients with anterior cruciate ligament tear admitted in department of orthopaedics, King George's Medical University, Lucknow. The present study had total of 50 subjects among which 25 were assigned in to two groups randomly, viz Group 1 of the treatment procedure - Quadruple hamstring graft alone and Group 2 of patients with augmented hamstring graft with fibertape. On comparing the improvement in grades at 12 weeks and 6 months follow-up, fiber group showed significantly more improvement compared with the non-fiber group. None of the cases in both the groups showed positive pivot shift test at 6 months follow up.

Conclusion: In our study it was found that the improvement in grades of anterior drawer test and Lachman test in fibertape augmented group was significantly more than the non-augmented group at 12 weeks and 6 months. Follow up period of 6 months was a limiting factor in our study. This technique needs further clinical evaluation to assess the long term results and the effect of protection of the graft and also to study the clinical behavior of the resultant collagen fibertape.

Keywords: Anterior drawer test lachman test, pivot shift test, lysholm knee score, ACL

\section{Introduction}

Anterior cruciate ligament (ACL) injury is the most common ligament injury in the knee ${ }^{[1]}$. Greater participation of the general population in sports and recreational activities continues to expose more individuals to the risk of ACL tear. The science and techniques of ACL reconstruction has increased over time. Various methods for reconstructing the ligament exist, including the use of patellar tendon auto graft, quadriceps tendon autograft, hamstring tendons, allograft materials and synthetic ligaments and tapes.

The ACL is the prime static stabilizer of the knee against anterior translation of tibia on femur ${ }^{[2]}$. The ACL originates from the medial surface of the lateral femoral condyle posteriorly in the intercondylar notch in the form of a segment of a circle ${ }^{[3]}$. The anterior side of the attachment is almost straight and the posterior side convex. The ligament courses anteriorly, distally, and medially toward the tibia. Over the length of its course the fibers of the ligament undergo slight external rotation. The average length of the ligament is $38 \mathrm{~mm}$, and the average width is $11 \mathrm{~mm}^{[4]}$.

The two bundles are defined by their respective tibial insertion with an anteromedial (AM) bundle and a posterolateral (PL) bundle. The AM bundle originates in the proximal part of the femoral origin and inserts in the anteromedialportion of the tibial insertion; in distinction, the PL bundle originates distally in the femoral origin and inserts in the posterolateral aspect of the tibial insertion ${ }^{[4]}$.

The standardised, Anterior Drawer test Lachman test, Pivot shift test, Lysholm knee score 
Quantified in terms of the side-to-side difference in laxity both preoperatively and postoperatively.

A rupture of the anterior cruciate ligament (ACL) significantly alters the kinematics and laxity of the knee joint $[5,6,7]$. It is uncertain how ACL reconstruction, the standard medical intervention for active people, is able to restore the kinematics of the involved joint ${ }^{[5,8]}$. The literature has demonstrated that the pivot-shift test, used for assessing rotatory and dynamic knee laxity, is associated with ACL deficiency and constitutes the most specific clinical tool for the examination of ACL ruptures ${ }^{[9]}$. Moreover, the pivot-shift test correlates to subjective instability ${ }^{[10]}$, reduced sport activity ${ }^{[11]}$, and articular and meniscal damage ${ }^{[12]}$. It should also be high-lighted that full recovery of postoperative laxity is not always achieved when compared with the preinjury level of laxity ${ }^{[13,14]}$. However, the functional behavior of the ACL graft at the time of reconstruction is not well understood, and the desired amount of restraint applied by the ACL graft and as compared with the healthy knee has not been fully clarified.

\section{Method}

This is aprospective cohort study conducted in dept. of orthopaedic, KGMU, Lucknow in Patients with Anterior Cruciate Ligament tear admitted to the department of Orthopaedics over a period of one year. Full inclusion and exclusion criteria for study eligibility are summarized in Table 1.

\section{Table 1}

Inclusion and Exclusion Criteria ${ }^{\mathrm{a}}$

\section{Inclusion criteria}

- Physically active patients in the age group 18-45 years unwilling to change their life style.

- Clinical / radiological / arthroscopic evidence of anterior cruciate ligament deficiency which remains symptomatic despite conservative therapy.

- Out of acute inflammatory phase of injury with full range of motion and no extensor lag.

\section{Exclusion criteria}

- Bilateral ACL tear.

- Lack of fitness due to associated comorbidity.

- Associated fractures of lower limbs and /or spine/ neurovascular injuries.

- Associated injuries to other ligaments of the knee.

- Significant Arthritis of the knee joint.

- Local skin infection.

ACL, anterior cruciate ligament.

All patients with anterior cruciate ligament tear fulfilling the inclusion criteria, subject to written informed consent and admitted to the department of Orthopaedics were assessed for

1. Age

2. Sex

3. Level of physical activity - Inactive/Light/ Moderate/ Vigorous

4. Duration since injury to intervention

5. Preoperative Lysholm knee score

6. Postoperative Lysholm knee score at 6 weeks, 12 weeks and 6 months

7. Preoperative Anterior Drawer test

8. Postoperative Anterior Drawer test at 6 weeks, 12 weeks and 6 months
9. Preoperative Lachman test

10. Postoperative Lachman test at 6 weeks, 12 weeks and 6 months

11. Preoperative Pivot shift test

12. Postoperative Pivot shift test at 6 weeks, 12 weeks and 6 months.

Patients were divided into two groups namely reconstruction with hamstring graft (Group A) and reconstruction with hamstring graft combined with augmentation using fiber tape (Group B) randomly.

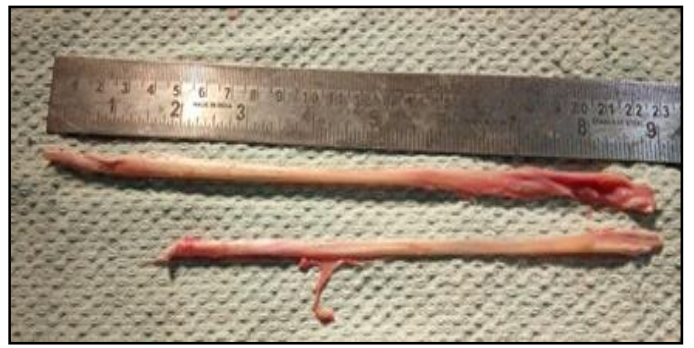

Fig 1: Harvested semitendinosus and gracilis auto graft

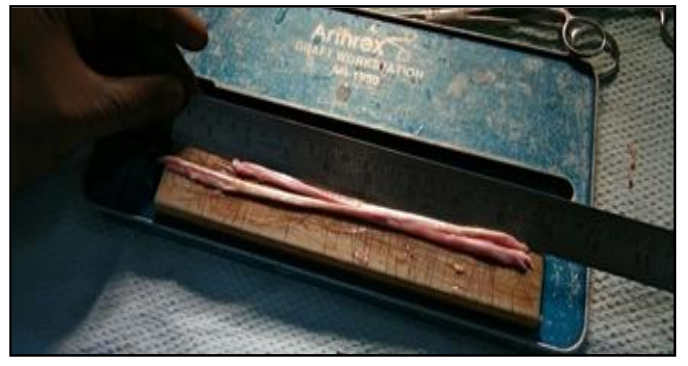

Fig 2: Graft placed on graft preparation board

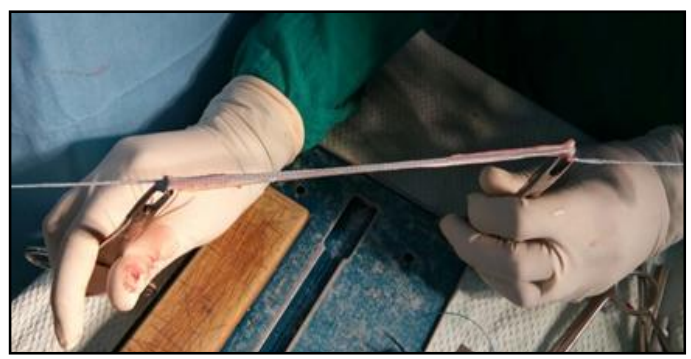

Fig 3: Graft sutured along with fibertape

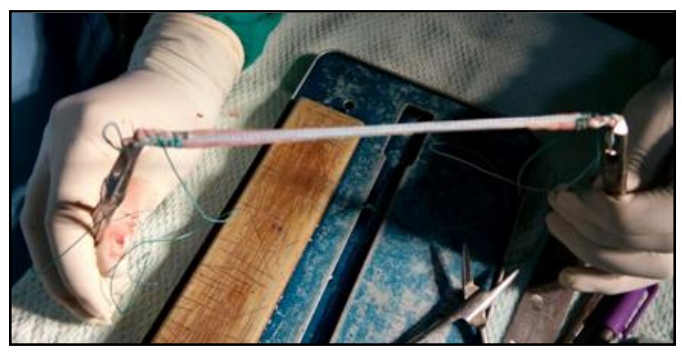

Fig 4: Prepared graft with fibertape along

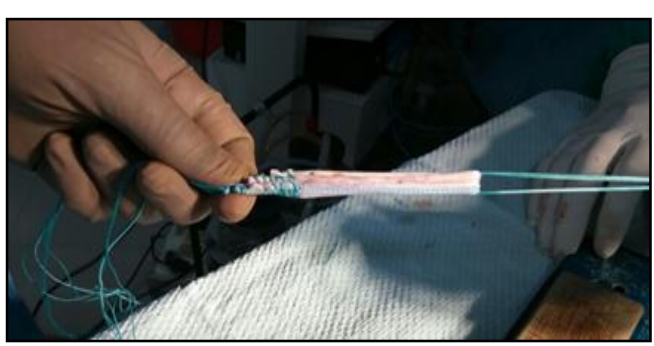

Fig 5: Quadrupled graft with fibertape along 
Rehabilitation protocol: Pre-operative rehabilitation

Rehabilitation should commence prior to surgery. After an ACL injury, deficits occur in strength ${ }^{[19]}$, proprioception ${ }^{[20,}$ ${ }^{21]}$, muscle timing ${ }^{[22]}$ and gait patterns ${ }^{[23]}$. In fact, strength and proprioceptive alterations occur in both the injured and uninjured knee ${ }^{[24]}$. The primary impairment with an ACL deficient knee is instability. This is manifested by episodes of 'giving way', which can lead to further joint damage and ultimately, long term degenerative changes ${ }^{[25]}$. Research has demonstrated that physiotherapy provided pre-operatively is effective in increasing strength and balance which may limit the number the episodes of 'giving way' and decrease the incidence of re-injury in the ACL deficient knee ${ }^{[26,27]}$. The main goals of a 'pre-rehabilitative' program prior to surgery include: full range of motion equal to the opposite knee, minimal joint swelling, adequate strength and neuromuscular control, and a positive state of mind ${ }^{[28]}$. All of these factors facilitate optimal post-operative recovery. It is important to maintain the highest level of strength and function possible in the unaffected leg as it will be used for comparison to assess the progress of the reconstructed knee, in the later stages of rehabilitation ${ }^{[29,30]}$.

\section{Post-operative rehabilitation \\ Week 1-2}

- Partial weight bearing with support of walker wearing ROM knee brace.

- $\quad$ Range of motion should be 10-90 degrees.

- Quadriceps and hamstring exercises.

\section{Weeks 2-4}

- $\quad$ Range of motion should be 0-110 degrees

- Walk wearing ROM knee brace with or without use of stick.

\section{Weeks 4-6}

- Range of motion should be 0-115 degrees

- Increase intensity of functional exercises

\section{Weeks 6-12}

- Full range of motion. Introduce training as able to demonstrate good mechanics and adequate strength.

- Walking without support with ROM knee brace.

\section{Weeks 12-24}

- Patients can begin jogging at 14 weeks assuming they have adequate quadriceps control and no complications. Their first few sessions of running should be monitored.

\section{Weeks $>24$ weeks}

- $\quad$ squatting allowed

- walking without knee brace

\section{Follow up protocol}

- Patient follow up will be done post-operatively at:

- 6 weeks, 12 weeks and 6 months clinically for functional status using Lysholm knee score and extensor lag

- Grading of laxity is to be evaluated by anterior drawer test, Lachman test and pivot shift test.

Case will be labeled as failure as per following criteria given by Noyes and Barber-Westin [31]

1. A complete graft tear with $>6 \mathrm{~mm}$ of anterior tibial displacement as compared to healthy knee or

2. A positive pivot shift test graded +2 or +3 compared to the healthy knee, with or without knee pain or inflammation, or subjective sensation of instability or functional limitations for daily life and/or sports activities.

Table 1: Lysholm knee score

\begin{tabular}{|c|c|c|}
\hline Parameters & Finding & Points \\
\hline \multirow{3}{*}{ 1. Limp (5 points) } & None & 5 \\
\hline & Slight or periodic & 3 \\
\hline & Severe and constant & 0 \\
\hline \multirow{3}{*}{ 2. Support (5 points) } & No support & 5 \\
\hline & Stick or crutch & 2 \\
\hline & Weight bearing impossible & 0 \\
\hline \multirow{4}{*}{ 3. Stairs climbing (10 points) } & No problem & 10 \\
\hline & Slightly impaired & 6 \\
\hline & One step at a time & 2 \\
\hline & Impossible & 0 \\
\hline \multirow{4}{*}{ 4. Squatting (5 points) } & No problem & 5 \\
\hline & Slightly impaired & 4 \\
\hline & Not past 90 degrees & 2 \\
\hline & Impossible & 0 \\
\hline \multirow{6}{*}{ 5. Instability ( 25 points) } & Never giving way & 25 \\
\hline & Rarely gives way except for athletic or other severe exertion & 20 \\
\hline & Gives way frequently during athletic events or severe exertion 20 & 15 \\
\hline & Occasionally in daily activities & 10 \\
\hline & Often gives way during daily activities & 5 \\
\hline & Gives way on every step & 0 \\
\hline \multirow{4}{*}{ 6. Swelling (10 points) } & None & 10 \\
\hline & On severe exertion & 6 \\
\hline & On ordinary exertion & 2 \\
\hline & Constant & 0 \\
\hline \multirow{5}{*}{ 7. Pain (25 points) } & None & 25 \\
\hline & Inconstant and slight during severe exertion & 20 \\
\hline & Marked pain during vigorous activities & 15 \\
\hline & Marked on or walking more than 1 mile $/ 2 \mathrm{~km}$ & 10 \\
\hline & Marked on or walking less than 1 mile $/ 2 \mathrm{~km}$ & 5 \\
\hline
\end{tabular}




\begin{tabular}{|l|c|c|}
\hline & Constant & 0 \\
\hline \multirow{4}{*}{ 8. Locking sensation in the knee --(15 points) } & No locking no catching sensation & 15 \\
\cline { 2 - 3 } & Catching sensation but no locking sensation & 10 \\
\cline { 2 - 3 } & Knee locks occasionally & 6 \\
\cline { 2 - 3 } & Knee locks frequently & 2 \\
\cline { 2 - 3 } & Locked joint on examination & 0 \\
\hline
\end{tabular}

The results are interpreted as follows if scores are

\begin{tabular}{|c|c|}
\hline$<65$ & $=$ Poor \\
\hline $65-83$ & $=$ Fair \\
\hline $84-90$ & $=$ Good \\
\hline$>91$ & $=$ Excellent \\
\hline
\end{tabular}

\section{Grading of anterior drawer and lachman tests}

$>$ Anterior translation of tibia on femur

- $\quad+3->10 \mathrm{~mm}$

- $\quad+2-5-10 \mathrm{~mm}$

- $\quad+1-<5 \mathrm{~mm}$

\section{Grading of pivot shift tests}

1. Gentle twisting slide with tibia twisting internally maximally;

2. Clunk with tibia neutral, negative when tibia externally rotated;

3. Painless glide for examiner and patient;

4. Jamming and Plowing, impingement;

Knee extension lag

Present $-\geq 5^{0}$

Absent $-<5^{0}$

\section{Observation and Results}

Table 2: Age distribution of subjects

\begin{tabular}{|c|c|c|c|c|}
\hline \multicolumn{5}{|c|}{ Age } \\
\hline Type & Mean & SD & Min. & Max. \\
\hline Non Fiber & 32.16 & 9.22 & 17 & 56 \\
\hline Fiber & 27.84 & 9.44 & 16 & 53 \\
\hline t-value & \multicolumn{5}{|c|}{1.604} \\
\hline p-value & \multicolumn{5}{|c|}{0.115} \\
\hline
\end{tabular}

The mean age of patients in Non Fiber groups was 32.16 \pm 9.22 years (Table-2) which was slightly more than the Fiber group where the mean age of patients was 27.84 \pm 9.44 years. However the difference in mean ages between the two groups was not found to be significant $(\mathrm{p}=0.115)($ Table-2).

Table 3: Sex distribution of subjects

\begin{tabular}{|c|c|c|c|c|c|c|}
\hline \multirow{2}{*}{ Sex } & \multicolumn{4}{|c|}{ Type } & \multirow{2}{*}{ Total } \\
\cline { 2 - 7 } & \multicolumn{2}{|c|}{ Non Fiber } & \multicolumn{2}{c|}{ Fiber } & \multicolumn{2}{c|}{} \\
\cline { 2 - 7 } & No. & \% & No. & \% & No. & \% \\
\hline Female & 5 & $20.00 \%$ & 4 & $16.00 \%$ & 9 & $18.00 \%$ \\
\hline Male & 20 & $80.00 \%$ & 21 & $84.00 \%$ & 41 & $82.00 \%$ \\
\hline Total & 25 & $100.00 \%$ & 25 & $100.00 \%$ & 50 & $100.00 \%$ \\
\hline chi sq & \multicolumn{6}{|c|}{0.136} \\
\hline p-value & \multicolumn{7}{|c|}{0.713} \\
\hline
\end{tabular}

In the non-fiber group there were $20.0 \%$ females and $80.0 \%$ males while the fiber group contained $16.0 \%$ females and $84.0 \%$ males (Table-3). Overall the study included $18.0 \%$ females and $82.0 \%$ males. The difference in female - male ratio between the two groups was not found to be significant $(\mathrm{p}=0.713)($ Table-3).

Table 4: Anterior drawer test results - intergroup comparison between non-fiber and fiber group

\begin{tabular}{|c|c|c|c|c|c|c|c|}
\hline \multirow{2}{*}{\multicolumn{2}{|c|}{ Anterior Drawer test }} & \multicolumn{4}{|c|}{ Type } & \multirow{2}{*}{\multicolumn{2}{|c|}{ Total }} \\
\hline & & \multicolumn{2}{|c|}{ Non Fiber } & \multicolumn{2}{|c|}{ Fiber } & & \\
\hline & & No. & $\%$ & No. & $\%$ & No. & $\%$ \\
\hline \multirow{4}{*}{ Pre-operative } & Grade 2 & 14 & $56.00 \%$ & 8 & $32.00 \%$ & 22 & $44.00 \%$ \\
\hline & Grade 3 & 11 & $44.00 \%$ & 17 & $68.00 \%$ & 28 & $56.00 \%$ \\
\hline & Chi sq & \multicolumn{6}{|c|}{2.922} \\
\hline & $\mathrm{p}$-value & \multicolumn{6}{|c|}{0.087} \\
\hline \multirow{4}{*}{$\begin{array}{l}6 \text { week Post- } \\
\text { operative }\end{array}$} & Grade 1 & 24 & $96.00 \%$ & 23 & $92.00 \%$ & 47 & $86.00 \%$ \\
\hline & Grade 2 & 1 & $4.00 \%$ & 2 & $8.00 \%$ & 3 & $14.00 \%$ \\
\hline & Chi sq & \multicolumn{6}{|c|}{0.355} \\
\hline & $\mathrm{p}$-value & \multicolumn{6}{|c|}{0.552} \\
\hline \multirow{4}{*}{$\begin{array}{c}12 \text { week Post- } \\
\text { operative }\end{array}$} & Grade 1 & 22 & $88.00 \%$ & 21 & $84.00 \%$ & 43 & $86.00 \%$ \\
\hline & Grade 2 & 3 & $12.00 \%$ & 4 & $16.00 \%$ & 7 & $14.00 \%$ \\
\hline & Chi sq & \multicolumn{6}{|c|}{0.166} \\
\hline & p-value & \multicolumn{6}{|c|}{0.684} \\
\hline \multirow{4}{*}{$\begin{array}{c}6 \text { month Post- } \\
\text { operative }\end{array}$} & Grade 1 & 22 & $88.00 \%$ & 24 & $96.00 \%$ & 46 & $92.00 \%$ \\
\hline & Grade 2 & 3 & $12.00 \%$ & 1 & $4.00 \%$ & 4 & $8.00 \%$ \\
\hline & Chi sq & \multicolumn{6}{|c|}{1.087} \\
\hline & $\mathrm{p}$-value & \multicolumn{6}{|c|}{0.297} \\
\hline
\end{tabular}

Pre operatively anterior drawer test grade 3 was seen in $44.0 \%$ cases of non-fiber group and $68.0 \%$ cases of fiber group. Remaining cases had grade 2 in both the groups. Pre operatively no significant difference was found in various grades proportion between the two groups $(\mathrm{p}=0.087)$ Post operatively after 6 weeks Anterior drawer test grade 3 was eliminated from both groups. Therefore improvement was found in both the groups. Grade 2 was seen in $4.0 \%$ cases of non-fiber group and $8.0 \%$ cases of fiber group. Majority had grade 1 in both non-fiber and fiber groups with proportion $96 \%$ and $92 \%$ respectively. However no significant difference was found between the two groups ( $\mathrm{p}=0.552)$ (Table-4).

Post operatively after 12 weeks anterior drawer test grade 3 was eliminated from both groups. Grade 2 was seen in $12.0 \%$ cases of non-fiber group and $16.0 \%$ cases of fiber group. Majority had grade 1 in both non-fiber and fiber groups with proportion $88 \%$ and $84 \%$ respectively. However no significant difference was found between the two groups $(\mathrm{p}=0.684)($ Table-4).

Post operatively after 6 months anterior drawer test grade 3 was eliminated from both groups. Grade 2 was again seen in $12.0 \%$ cases of non fiber and $4.0 \%$ cases of fiber group. Grade 1 was seen in $88 \%$ of non-fiber groups and $96.0 \%$ of fiber group. However no significant difference was found between the two groups $(\mathrm{p}=0.297)$ (Table-4).

Considering Grade 3 to Grade 1 shifting as improvement of level 2 and Grade 2 to Grade 1 or grade 3 to Grade 2 shifting as improvement of level 1. Following table was made to compare improvements between the groups. 
Table 5: Intergroup comparison of improvements in grades of anterior drawer test

\begin{tabular}{|c|c|c|c|c|c|c|c|}
\hline \multirow{2}{*}{ Time } & \multirow{2}{*}{ Improvement level } & \multicolumn{2}{|c|}{ Non Fiber } & \multicolumn{2}{|c|}{ Fiber } & \multirow{2}{*}{ chi sq } & \multirow{2}{*}{ p-value } \\
\cline { 2 - 7 } & & No. & $\mathbf{\%}$ & No. & \% & & \\
\hline \multirow{2}{*}{ 6 week } & Level - 1 & 14 & $56.00 \%$ & 9 & $36.00 \%$ & \multirow{2}{*}{2.013} & \multirow{2}{*}{0.156} \\
\cline { 2 - 7 } & Level - 2 & 11 & $44.00 \%$ & 14 & $56.00 \%$ & & \\
\hline \multirow{2}{*}{12 week } & Level - 1 & 16 & $64.00 \%$ & 8 & $32.00 \%$ & \multirow{2}{*}{5.128} & \multirow{2}{*}{0.024} \\
\cline { 2 - 6 } & Level - 2 & 9 & $36.00 \%$ & 17 & $68.00 \%$ & & \\
\hline \multirow{3}{*}{6 month } & Unchange & 2 & $8.00 \%$ & 0 & $0.00 \%$ & \multirow{3}{*}{6.29} & \multirow{2}{*}{0.043} \\
\cline { 2 - 6 } & Level - 1 & 16 & $64.00 \%$ & 10 & $40.00 \%$ & & \\
\cline { 2 - 6 } & Level - 2 & 7 & $28.00 \%$ & 15 & $60.00 \%$ & & \\
\hline
\end{tabular}

On comparing the improvement in grades of ADT, after 6 weeks the fiber group showed 56.0\% improvement of level 2 and $44.0 \%$ improvement of level - 1 while non-fiber group showed $44.0 \%$ improvement of level -2 and $56.0 \%$ improvement of level -1 . However no significant difference in various improvement levels was found between the two groups. $(\mathrm{p}=0.156)$ (Table-5).

After 12 weeks the fiber group showed $68.0 \%$ improvement of level -2 and $32.0 \%$ improvement of level -1 while nonfiber group showed only $36.0 \%$ improvement of level -2 and remaining $64.0 \%$ improvement of level -1 . Fiber group showed significantly more improvement than the non fiber group. $(\mathrm{p}=0.024)($ Table-5).

After 6 month the fiber group showed $60.0 \%$ improvement of level -2 and $40.0 \%$ improvement of level -1 while non-fiber group showed only $28.0 \%$ improvement of level -2 and $64.0 \%$ improvement of level -1 . Fiber group showed significantly more improvement than the non fiber group. $(\mathrm{p}=0.043)($ Table-5).

Pre operatively Lachman test grade 3 was seen in $36.0 \%$ cases of non-fiber group and $72.0 \%$ cases of fiber group. Remaining cases had grade 2 in both the groups (Table-6). Pre operatively a significant difference was found in grades between the two groups $(\mathrm{p}=0.011)$ (Table-6).

Post operatively after 6 weeks Lachman test grade 3 was eliminated from both groups. Grade 2 was seen in $4.0 \%$ cases of non-fiber group and $8.0 \%$ cases of fiber group. Majority had grade 1 in both non-fiber and fiber groups with proportion $96 \%$ and $92 \%$ respectively (Table-6). However no significant difference was found between the two groups $(\mathrm{p}=0.552)$ (Table-6).

Post operatively after 12 weeks Lachman test grade 3 was eliminated from both groups. Grade 2 was seen in $12.0 \%$ cases of non-fiber group and $8.0 \%$ cases of fiber group. Majority had grade 1 in both non-fiber and fiber groups with proportion $88 \%$ and $92 \%$ respectively (table-6). However no significant difference was found between the two groups $(\mathrm{p}=0.637)$ (Table-6).

Post operatively after 6months Lachman test grade 3 was eliminated from both groups. Grade 2 was seen in $16.0 \%$ cases of non-fiber group and $8.0 \%$ cases of fiber group. Majority had grade 1 in both non-fiber and fiber groups with proportion $84 \%$ and $92 \%$ respectively (Table-6). However no significant difference was found between the two groups $(\mathrm{p}=0.384)($ Table-6).

Table 6: Lachman Test Results

\begin{tabular}{|c|c|c|c|c|c|c|c|}
\hline \multirow{3}{*}{\multicolumn{2}{|c|}{ Lachman's test }} & \multicolumn{4}{|c|}{ Type } & \multirow{2}{*}{\multicolumn{2}{|c|}{ Total }} \\
\hline & & \multicolumn{2}{|c|}{ Non Fiber } & \multicolumn{2}{|c|}{ Fiber } & & \\
\hline & & No. & $\%$ & No. & $\%$ & No. & $\%$ \\
\hline \multirow{4}{*}{ Pre-operative } & Grade 2 & 16 & $64.0 \%$ & 7 & $28.0 \%$ & 23 & $46.0 \%$ \\
\hline & Grade 3 & 9 & $36.0 \%$ & 18 & $72.0 \%$ & 27 & $54.0 \%$ \\
\hline & chi sq & \multicolumn{6}{|c|}{6.522} \\
\hline & p-value & \multicolumn{6}{|c|}{0.011} \\
\hline \multirow{4}{*}{6 week Post-operative } & Grade 1 & 24 & $96.0 \%$ & 23 & $92.0 \%$ & 47 & $94.0 \%$ \\
\hline & Grade 2 & 1 & $4.0 \%$ & 2 & $8.0 \%$ & 3 & $6.0 \%$ \\
\hline & chi sq & \multicolumn{6}{|c|}{0.355} \\
\hline & $\mathrm{p}$-value & \multicolumn{6}{|c|}{0.552} \\
\hline \multirow{4}{*}{12 week Post-operative } & Grade 1 & 22 & $88.0 \%$ & 23 & $92.0 \%$ & 45 & $90.0 \%$ \\
\hline & Grade 2 & 3 & $12.0 \%$ & 2 & $8.0 \%$ & 5 & $10.0 \%$ \\
\hline & chi sq & \multicolumn{6}{|c|}{0.222} \\
\hline & $\mathrm{p}$-value & \multicolumn{6}{|c|}{0.637} \\
\hline \multirow{4}{*}{6 month Post-operative } & Grade 1 & 21 & $84.0 \%$ & 23 & $92.0 \%$ & 44 & $88.0 \%$ \\
\hline & Grade 2 & 4 & $16.0 \%$ & 2 & $8.0 \%$ & 6 & $12.0 \%$ \\
\hline & chi sq & \multicolumn{6}{|c|}{.758} \\
\hline & $\mathrm{p}$-value & \multicolumn{6}{|c|}{0.384} \\
\hline
\end{tabular}

On comparing the improvement in grades of Lachman test, after 6 weeks the fiber group showed $60.0 \%$ improvement of level -2 and $40.0 \%$ improvement of level -1 while non-fiber group showed $44.0 \%$ improvement of level -2 and $56.0 \%$ improvement of level - 1 (Table-7). However no significant difference in various improvement levels was found between the two groups. $(\mathrm{p}=0.258)$ (Table-7).

Table 7: Intergroup comparison of improvements in grades of lachman test

\begin{tabular}{|c|c|c|c|c|c|c|c|}
\hline \multirow{2}{*}{ Time } & \multirow{2}{*}{ Improvement level } & \multicolumn{2}{|c|}{ Non Fiber } & \multicolumn{2}{|c|}{ Fiber } & \multirow{2}{*}{ chi sq } & \multirow{2}{*}{ p-value } \\
\hline & & No. & $\%$ & No. & $\%$ & & \\
\hline \multirow{2}{*}{6 week } & Level - 1 & 14 & $56.0 \%$ & 10 & $40.0 \%$ & \multirow{2}{*}{1.282} & \multirow{2}{*}{0.258} \\
\hline & Level - 2 & 11 & $44.0 \%$ & 15 & $60.0 \%$ & & \\
\hline \multirow{2}{*}{12 week } & Level - 1 & 16 & $64.0 \%$ & 8 & $32.0 \%$ & \multirow{2}{*}{5.13} & \multirow{2}{*}{0.024} \\
\hline & Level - 2 & 9 & $36.0 \%$ & 17 & $68.0 \%$ & & \\
\hline \multirow{3}{*}{6 month } & Unchange & 2 & $8.0 \%$ & 1 & $4.0 \%$ & \multirow{3}{*}{$6.48 *$} & \multirow{3}{*}{0.039} \\
\hline & Level - 1 & 15 & $60.0 \%$ & 7 & $28.0 \%$ & & \\
\hline & Level - 2 & 8 & $32.0 \%$ & 17 & $68.0 \%$ & & \\
\hline
\end{tabular}


After 12 weeks the fiber group showed $68.0 \%$ improvement of level -2 and $32.0 \%$ improvement of level - 1 while nonfiber group showed only $36.0 \%$ improvement of level -2 and remaining $64.0 \%$ improvement of level -1 (Table-7). Fiber groups showed significantly more improvement than the non fiber group. $(\mathrm{p}=0.024)$ (Table-7).
After 6 months the fiber group showed $68.0 \%$ improvement of level -2 and $28.0 \%$ improvement of level -1 while nonfiber group showed only $32.0 \%$ improvement of level -2 and remaining $60.0 \%$ improvement of level - 1(Table-7). Fiber groups showed significantly more improvement than the non fiber group. $(\mathrm{p}=0.039)$ (Table-7).

Table 8: Knee extension lag status

\begin{tabular}{|c|c|c|c|c|c|c|}
\hline \multirow{3}{*}{\multicolumn{2}{|c|}{ knee extension lag }} & \multicolumn{3}{|c|}{ Type } & \multirow{2}{*}{\multicolumn{2}{|c|}{ Total }} \\
\hline & & \multicolumn{2}{|c|}{ Non Fiber } & Fiber & & \\
\hline & & No. & No & $\%$ & \begin{tabular}{|l|} 
No. \\
\end{tabular} & $\%$ \\
\hline \multirow{4}{*}{ Pre-operative } & Present & 4 & $16.0 \%$ & $8.0 \%$ & 6 & $12.0 \%$ \\
\hline & Absent & 21 & $84.0 \%$ & $92.0 \%$ & 44 & $88.0 \%$ \\
\hline & chi sq & \multicolumn{5}{|c|}{0.758} \\
\hline & p-value & \multicolumn{5}{|c|}{0.384} \\
\hline \multirow{4}{*}{6 week } & Present & \multirow{2}{*}{\multicolumn{2}{|c|}{$\begin{array}{c}8.0 \% \\
92.0 \%\end{array}$}} & $4.0 \%$ & 3 & $6.0 \%$ \\
\hline & Absent & & & $96.0 \%$ & 47 & $94.0 \%$ \\
\hline & chi sq & \multicolumn{5}{|c|}{0.355} \\
\hline & p-value & \multicolumn{5}{|c|}{0.552} \\
\hline \multirow{3}{*}{12 week } & Absent & 25 & $100.0 \%$ & $100.0 \%$ & 50 & $100.0 \%$ \\
\hline & chi sq & \multicolumn{5}{|c|}{ NA } \\
\hline & p-value & \multicolumn{5}{|c|}{ NA } \\
\hline \multirow{3}{*}{6 month Post-operative } & Absent & 25 & $100.0 \%$ & \begin{tabular}{|l|l|}
25 & $100.0 \%$
\end{tabular} & 50 & $100.0 \%$ \\
\hline & chi sq & \multicolumn{5}{|c|}{ NA } \\
\hline & p-value & \multicolumn{5}{|c|}{ NA } \\
\hline
\end{tabular}

Pre operatively Knee extension lag was present in $16.0 \%$ cases of non-fiber group and $8.0 \%$ cases of fiber group (Table-8). Pre operatively no significant difference was found in knee extension lag between the two groups $(\mathrm{p}=0.384)$ (Table-8)

Post operatively after 6 weeks Knee extension lag was present in $8.0 \%$ cases of non-fiber and $4.0 \%$ cases of fiber groups (Table-8). Post operatively no significant difference was found in knee extension lag between the two groups $(\mathrm{p}=0.552)($ Table-8)

Post operatively after 12 weeks and onwards Knee extension lag was absent in all the cases (Table-8).

Table 9: Lysholm knee score comparison between the fiber \& non fibre

\begin{tabular}{|c|c|c|c|c|c|c|}
\hline \multirow{2}{*}{ Lysholm Knee Score } & \multicolumn{2}{|c|}{ Non Fiber } & \multicolumn{2}{|c|}{ Fiber } & \multirow{2}{*}{ t-value } & \multirow{2}{*}{ p-value } \\
\cline { 2 - 6 } & Mean & SD & Mean & SD & & \\
\hline Pre-operative & 64.5 & 8.88 & 63.78 & 9.19 & 0.392 & .784 \\
\hline 6 week & 74.92 & 5.66 & 75.82 & 5.77 & 0.121 & 0.904 \\
\hline 12 week & 81.14 & 5.06 & 80.02 & 5.04 & 0.192 & .848 \\
\hline 6 month & 87.02 & 4.77 & 86.96 & 4.98 & 0.313 & .756 \\
\hline
\end{tabular}

Pre operatively mean Lysholm knee score for the non-fiber group was $64.5 \pm 8.88$ while for the fiber group it was $63.78 \pm 9.19$ (Table-9). The difference was insignificant $(\mathrm{p}=0.784)$ (Table-9).

Post operatively after 6 weeks mean Lysholm knee score for the non-fiber group was 74.92 \pm 5.66 while for the fiber group it was 75.82 \pm 5.77 (Table-9). Again the difference between the two groups was insignificant $(\mathrm{p}=.904)$ (Table-9).

Post operatively after 12 weeks mean Lysholm knee score for the non-fiber group was $81.14 \pm 5.06$ while for the fiber group it was $80.02 \pm 5.04$ (Table-9). Was increased but insignificant $(\mathrm{p}=0.848)($ Table-9).

Post operatively after 6 months mean Lysholm knee score for the non-fiber group was 87.02 \pm 4.77 while for the fiber group it was $86.96 \pm 4$. 98 (Table-9). Was insignificant $(\mathrm{p}=0.756)$ (Table-9).

\section{Discussion}

The present study was conducted on patients with anterior cruciate ligament tear admitted in department of orthopaedics, King george's medical university, Lucknow. The study was conducted with an aim to measure the additional effect of using Fiber-tape along with hamstring graft on functional outcome of anterior cruciate ligament reconstruction.

The present study had total of 50 subjects among which 25 were assigned in to two groups randomly, viz Group 1 of the treatment procedure - Quadruple hamstring graft alone and Group 2 of patients with augmented hamstring graft with fibertape. Mark D. Santi et al ${ }^{[15]}$, in their study compared 28 patients of ligament augmentation device in the semitendinosus and gracilis tendons with 32 patients who had reconstruction with semitendinosus and gracilis tendons alone.

Our observations of the present study has been discussed under the following headings.

1. Age distribution of the patients

2. Gender distribution of patients

3. Assessment in functional recovery of the patients using lysholm knee score at different follow-ups in the postoperative period

4. Assessment of anterior drawer test at different follow-ups in the postoperative period

5. Assessment of lachmann test at different follow-ups in the postoperative period

6. Age distribution of the patients

The mean age of patients in Non Fiber group was 32.16 \pm 9.22 years which was slightly more than the Fiber group where the mean age of patients was 27.84 \pm 9.44 years. However the difference in mean ages between the two groups was not found to be significant $(\mathrm{p}=0.115)$. In study of Mark d santi et al. ${ }^{[15]}$, the mean age group of patients with ligament augmentation device were 27.3 \pm 7.0 , and those in nonligament augmentation device were $24.3 \pm 7.3$ and there was no significant differences between the two groups in terms of 
age distribution. Riel KA et al. ${ }^{[16]}$ in their study had 31 cases with patellar tendon graft and 50 cases with a quadricepspatellar periosteum-patellar tendon auto graft (MarshallMacIntosh) augmented with the Kennedy Ligament augmentation device (LAD).

1. Gender distribution of patients the male-female ratio in non fiber group was $80.0 \%: 20.0 \% \%$, while in fiber group was $84.0 \%: 16.0 \% \%$. Mark d santi et al ${ }^{[15]}$ in their study had a male female ratio in LAD group as $75: 25 \%$, while in non - LAD group it was 71.87: 28.13\%. Most of the patients in both the groups were males probably because males are more active, spend more time outwards and exposed to injuries as compared to females in our Indian set up. Since the patients in both the groups were similar with regards to age and sex distribution, we can infer that patients in both the groups were similar and therefore comparable.

2. Assessment in functional recovery of the patients using Lysholm knee score at different follow-ups in the postoperative period Mean Lysholm knee score in nonfiber group was 74.92, 81.14 and 87.02 at 6 weeks, 12 weeks and 6 months follow-up respectively, the intragroup improvement being statistically significant. While in fiber group it was 75.82, 80.02, and 86.96 at 6 weeks, 12 weeks and 6 months follow-up respectively, the intragroup improvement being statistically significant. However the difference in Lysholm knee score between the two groups during the follow up weeks was insignificant. Mark d santi et al ${ }^{[15]}$ in their study had a mean Lysholm knee score of 89.8 in ligament augmentation device group and 92.0 in the non-ligament augmentation device group. However the mean postoperative Lysholm score for the ligament augmentation device group was not statistically different from that of the non- ligament augmentation device group.

3. Assessment of anterior drawer test at different follow-ups in the postoperative period. Post operatively after 6 weeks anterior drawer test grade 3 was eliminated from both groups. Therefore improvement was found in both the groups. Grade 2 was seen in 1 cases of non-fiber group and 2 cases of fiber group. However no significant difference was found between the two groups $(\mathrm{p}=0.552)$. Post operatively after 12 weeks anterior drawer test grade 3 was eliminated from both groups. Grade 2 was seen in 3 cases of non-fiber group and 4 cases of fiber group. Majority had grade 1 in both non-fiber and fiber groups. However no significant difference was found between the two groups $(\mathrm{p}=0.684)$. Post operatively after 6 months anterior drawer test grade 2 was seen in 3 cases of non fiber and 1 cases of fiber group. The rest had grade 1 anterior drawer test. However no significant difference was found between the two groups $(\mathrm{p}=0.297)$ Among the 25 patients in non-fiber group who underwent ACL reconstruction, three patients had grade 2 anterior drawer test, rest all patients had grade 1 anterior drawer test at 6 months follow-up. But among the 25 patients in the fiber group, one patient had grade 2 anterior drawer test, rest all patients had grade 1 anterior drawer test at 6 months follow-up. On comparing the improvement in grades at 12 weeks and 6 months follow-up, fiber group showed significantly more improvement compared with the nonfiber group.

4. Assessment of Lachman test at different follow-ups in the postoperative period Post operatively at 6 weeks
Lachman test grade 3 was eliminated from both groups. Grade 2 was seen in 1 case of non-fiber group and 2 cases of fiber group. Majority had grade 1 in both nonfiber and fiber groups with proportion $96 \%$ and $92 \%$ respectively. However no significant difference was found between the two groups $(\mathrm{p}=0.552)$ Post operatively after 12 weeks Lachman test Grade 2 was seen in 3 cases of non-fiber group and 2 case of fiber group. Majority had grade 1 in both non-fiber and fiber groups with proportion $92 \%$ and $96 \%$ respectively. However no significant difference was found between the two groups $(\mathrm{p}=0.637)$ four patients in non-fiber group had grade 2 Lachman test, rest all patients had grade 1 Lachman test at 6 months follow-up. But among the 25 patients in the fiber group, two patient had grade 2 Lachman test, rest all patients had grade 1 Lachman test at 6 months follow-up. However no significant difference was found between the two groups $(\mathrm{p}=0.384)$. On comparing the improvement in grades at each follow-up, fiber group showed significantly more improvement at 12 weeks and 6 months compared with the non-fiber group. Mark d santi et al ${ }^{[15]}$ in their study had no difference statistically between the ligament augmentation device and nonligament augmentation device group. None of the cases in both the groups showed grade 3 positive for Lachman and anterior drawer test at 6 months follow up. None of the cases in both the groups showed positive pivot shift test at 6 months follow up. Harvesting the semitendinosus tendon alone without the gracilis avoids flexion and internal rotation strength deficits ${ }^{[17,18]}$. Adding fiber tape to the semitendinosus graft can avoid gracilis harvesting and the complications relating to it such as reduction in flexion and internal rotation strengths. Adding a synthetic fibertape to augment hamstring autograft in ACL reconstruction offers theoretical advantages but many questions remain unanswered. Stress shielding of the autograft may be beneficial in the early revascularization phase, but the continued effect of long-term stress shielding on the ultimate tensile properties of the graft is still unknown. Mark D. Santi et al [15], found no difference in the objective criteria (KT-1000 arthrometer testing, presence of pivot shift, or Lachman knee score) to suggest that the ligament augmentation device improved graft performance. Examining subjective data (Lysholm knee score, return to Tegner activity levels, and overall subjective rating) likewise revealed no significant difference in the two groups. Mark D. Santi et al ${ }^{[15]}$ in their study, 4 of 28 patients (14\%) with ligament augmentation device had recurrent symptomatic effusions. Removal of the synthetic material was helpful in all patients. None of the patients in our study developed such a complication.

One of the limitations of our study is a short follow-up period as long term effect of the fibertape on graft could not be evaluated.

\section{Conclusion}

In our study it was found that the improvement in grades of anterior drawer test and Lachman test in fibertape augmented group was significantly more than the non-augmented group at 12 weeks and 6 months.

Improvement in the subjective Lysholm knee score was found to be equal in both the groups with no significant difference between the two. 
Pivot shift test was absent in all the patients of reconstructed group postoperatively thus improving the rotational stability of the knee. All patients had full extension at 6 months follow up.

Addition of fibertape with hamstring graft did not develop any postoperative effusions or allergic reactions in our study.

The fibertape may act as a secondary stabilizer of the knee thus preventing injury or graft elongation over time. It may also add to the thickness of small diameter grafts of $<8 \mathrm{~mm}$.

Follow up period of 6 months was a limiting factor in our study. This technique needs further clinical evaluation to assess the long term results and the effect of protection of the graft and also to study the clinical behavior of the resultant collagen fibertape.

\section{References}

1. Granan LP, Forssblad M, Lind M et al. The Scandinavian ACL registries 2004-2007: baseline epidemiology. Acta Orthop. 2009; 80:563.

2. Butler DL, Noyes FR, Grood ES. Ligamentous restraints to anterior-posterior drawer in the human knee: a biomechanical study. J Bone Joint Surg Am. 1980; 62:259.

3. Girgis FG, Marshall JL, Al Monajem ARS. The cruciate ligaments of the knee joint. Clin Orthop. 1975; 106:216.

4. Amis AA, Dawkins GPC: Functional anatomy of the anterior cruciate ligament. J Bone Joint Surgery Br. 1991; 73:260.

5. Brandsson S, Karlsson J, Eriksson BI, Kärrholm J. Kinematics after tear in the anterior cruciate ligament: dynamic bilateral radiostereo-metric studies in 11 patients. Acta Orthop Scand. 2001; 72:372-378.

6. Bulgheroni P, Bulgheroni MV, Andrini L, Guffanti P, Giughello A. Gait patterns after anterior cruciate ligament reconstruction. Knee Surg Sports Traumatol Arthrosc. 1997; 5:14-21.

7. Kim K, Jeon K, Mullineaux DR, Cho E. A study of isokinetic strength and laxity with and without anterior cruciate ligament injury. J Phys Ther Sci. 2016; 28:32723275 .

8. Sundemo D, Alentorn-Geli E, Hoshino Y, Musahl V, Karlsson J, Samuelsson K. Objective measures on knee instability: dynamic tests. A review of devices for assessment of dynamic knee laxity through utilization of the pivot shift test. Curr Rev Musculoskelet Med. 2016; 9(2):148-159.

9. Prins M. The Lachman test is the most sensitive and the pivot shift the most specific test for the diagnosis of ACL rupture. Aust J Physiother. 2006; 52:66

10. Kujala UM, Nelimarkka O, Koskinen SK. Relationship between the pivot shift and the configuration of the lateral tibial plateau. Arch Orthop Trauma Surg. 1992; 111:228-229.

11. Kaplan Y. Identifying individuals with an anterior cruciate ligament-deficient knee as copers and noncopers: a narrative literature review. J Orthop Sports Phys Ther. 2011; 41:758-766.

12. Noyes FR, Matthews DS, Mooar PA, Grood ES. The symptomatic anterior cruciate-deficient knee, part II: the results of rehabilitation, activity modification, and counseling on functional disability. J Bone Joint Surg Am. 1983; 65:163-174.

13. Kuroda R, Hoshino Y, Kubo S et al. Similarities and differences of diagnostic manual tests for anterior cruciate ligament insufficiency: a global survey and kinematics assessment. Am J Sports Med. 2012; 40:91-99

14. Lie DTT, Bull AMJ, Amis AA. Persistence of the mini pivot shift after anatomically placed anterior cruciate ligament reconstruction. Clin Orthop Relat Res. 2007; 457:203-209.

15. Mark Santi D, Allen Richardson B. The ligament augmentation device in hamstring grafts for reconstruction of the anterior cruciate ligament. American lournal of sports medicine, 1994, 524-530.

16. Riel KA, Ulm K, Bernett P. Value of synthetic (Kennedy-LAD) augmentation in replacement of the anterior cruciate ligament. Unfallchirurg. 1991; 94(7):351-4.

17. Adachi N, Ochi M, Uchio Y, Sakai Y, Kuriwaka M, Fujihara A. Harvesting hamstring tendons for ACL reconstruction influences postoperative hamstring muscle performance. Arch Orthop Trauma Surg. 2003; 123:4605.

18. Segawa H, Omori G, Koga Y, Kameo T, Iida S, Tanaka M. Rotational muscle strength of the limb after anterior cruciate ligament reconstruction using semitendinosus and gracilis tendon. Arthroscopy. 2002; 18:177-82.

19. Natri A, Jarvinen M, Latvala K, Kannus P. Isokinetic muscle performance after anterior cruciate ligament surgery. Long-term results and outcome predicting factors after primary surgery and late-phase reconstruction. International Journal of Sports Medicine. 1996; 17:223-228.

20. Ochi M, Iwasa J, Uchio Y, Adachi N, Sumen Y. The regeneration of sensory neurons in the reconstruction of the anterior cruciate ligament. Journal of Bone and Joint Surgery (Br). 1999; 81:902-906.

21. Zatterstrom R, Friden T, Lindstrand A, Moritz U. The effect of physiotherapy on standng balance in chronic anterior cruciate ligament insufficiency. The American Journal of Sports Medicine. 1994; 22(4):531-536.

22. Wojtys EM, Huston LJ. Neuromuscular performance in normal and anterior cruciate ligament-deficient lower extremities. The American Journal of Sports Medicine. 1994; 22:531-536.

23. DeVita P, Hortobagyi T, Barrier J. Gait biomechanics are not normal after anterior cruciate ligament reconstruction and accelerated rehabilitation. Medicine and Science in Sports and Exercise. 1998; 30(10)1481-1488.

24. Corrigan JP, Cashman WF, Brady MP. Proprioception in the cruciate deficient knee. Journal of Bone and Joint Surgery (Br). 1992; 74:247-250.

25. Gillquist J, Messner K. Anterior cruciate ligament reconstruction and the long term incidence of gonarthrosis. Sports Medicine. 1999; 27(3):143-156.

26. Fitzgerald GK, Axe MJ, Snyder-Mackler L. The efficacy of perturbation training in nonoperative anterior cruciate ligament rehabilitation programs for physically active individuals. Physical Therapy. 2000; 80(2):128-151.

27. Keays SL, Bullcok-Saxton JE, Newcombe P, Bullock MI. The effectiveness of a pre-operative home-based physiotherapy programme for chronic anterior cruciate ligament deficiency. Physiotherapy Research International. 2006; 11(4):204-218.

28. Shelbourne KD, Patel DV. Timing of surgery in anterior cruciate ligament-injured knees. Knee Surgery, Sports Traumatology, Arthroscopy. 1995; 3:148-156.

29. Hiemstra LA, Webber S, MacDonald PB, Kriellaars DJ. Contralateral limb strength deficits after anterior cruciate ligament reconstruction using a hamstring tendon graft. 
Clinical Biomechanics. 2007; 22:543-550.

30. Hiemstra LA, Webber S, MacDonald PB, Kriellaars DJ. Knee strength deficits after hamstring and patellar tendon anterior cruciate ligament reconstruction. Medicine and Science in Sports and Exercise. 2000; 32(8):1472-1479.

31. Noyes FR, Barber-Westin SD. Revision anterior cruciate surgery with use of bone-patellar tendon-bone autogenous grafts. J Bone Joint Surg Am. 2001; 83(8):1131-43. 